\title{
Energy Efficient Inverters for Wind Energy Applications
}

\author{
Yogesh Patel \\ Rockwell Automation \\ Mequon, WI, USA \\ yppatel@ra.rockwell.com
}

\begin{abstract}
In this paper, efficiency and standby mode of operation of power conversion unit for wind power application is investigated. Mathematical model to calculate the power losses in three phase voltages source inverters, LCL filters, DC link capacitors and disconnect switches are presented. A comparison of inverter losses with sinusoidal pulse width modulation (PWM), space vector PWM and discontinuous PWM (DPWM) is discussed. Selection of power modules based on switching frequency, effect of modulation and gate resistance are presented. Techniques to improve the efficiency of the power conversion units are provided. The standby mode of operation is proposed to saves energy during unavailability of wind power. Efficiency of power conversion unit is calculated based on mathematical model and compare it with actual measurement.
\end{abstract}

\section{INTRODUCTION}

In recent years, wind energy has gained popularity due to several persisting problems with fossil based fuels. Voltage source inverter based power conversion units are used for renewable power conversions. The power conversion unit consists of pre-charge circuitry, LCL filter, VSI, DC link capacitor and VSC (voltage source converter) or CSC (current source converter) as shown in Figure 1. The precharge is used to charge the DC link capacitor as well as filter capacitor of the LCL filter. It is also served as a disconnect tool to isolate from the grid in case of the fault or routine maintenance. LCL filter is used to filter out the switching frequency components and to be able to meet the requirements of low harmonic standard IEEE 519. VSI converts the DC power to AC and interfaces with the grid. DC link capacitor helps reducing the DC bus ripple. The efficiency of the power conversion unit is important to save energy. Calculating efficiency requires mathematic models to calculate losses for each section of the power conversion unit. In the following section, power loss calculations are presented for LCL filter, VSI and DC link capacitors. The techniques to reduce the losses are presented. In addition, when wind is not available, it is important to place the power conversion unit in standby mode to save energy consumption. The energy saving mode is discussed in detail in section $(\mathrm{V})$.

\author{
Adel Nasiri \\ University of Wisconsin- Milwaukee \\ Milwaukee, WI, USA \\ nasiri@uwm.edu
}

II. POWER LOSS IN LCL FILTER

\section{A. Core loss}

The losses in LCL filter are divided in to core losses and copper losses. The core loss of the LCL filter inductor can be calculated using the Steinmetz equation.

$$
P_{\text {Core_loss }}=k f^{\alpha} B^{\beta}
$$

Where the $f$ is frequency of the magnetic field, $\mathrm{B}$ is flux density, $\alpha$ and $\beta$ are the coefficient. The total core losses can be divided in to three component: hysteresis losses $\mathrm{P}_{\mathrm{h}}$, eddy current losses $\mathrm{P}_{\mathrm{e}}$ and excess losses $\mathrm{P}_{\mathrm{a}}$ as shown in equations (2) and (3)[1].

$$
\begin{aligned}
& P_{\text {Core_loss }}=P_{h}+P_{e}+P_{a} \\
& P_{\text {Core_loss }}=k_{h} f B^{n}+k_{e} f^{2} B^{2}+k_{a} f^{1.5} B^{1.5}
\end{aligned}
$$

Where the $k_{h}, k_{e}$ and $\mathrm{n}$ are the coefficients, which depend on the lamination material, thickness, and conductivity of the material. $k_{a}$ is related to the material thickness, cross sectional area, conductivity and the material microstructure. The equation is only applicable for the sinusoidal flux density of varying magnitude and frequency. Modified steinmezt equation (MSE) is used to predict the losses of with non-sinusoidal waveforms [2][3].

$$
P_{M S E_{-} \text {Core_loss }}=k f_{e q}^{\alpha^{\alpha}} B^{\beta}
$$

Where $f_{e q}$ is an equivalent frequency. $f_{e q}=f$ for sine wave and for waveform other than sine wave can be calculated using equation (5).

$$
f_{e q}=\frac{2}{\left(2 \pi \frac{B_{p p}}{2}\right)^{2}} \int_{0}^{T}\left(\frac{d B}{d t}\right)^{2} d t
$$

Use of grain oriented silicon steel and reduce lamination thickness can lower the core losses. In addition reduce the length of each air gap and increase the number of air gap with keeping the total air gap length constant can recues the fringing effect and core losses. 


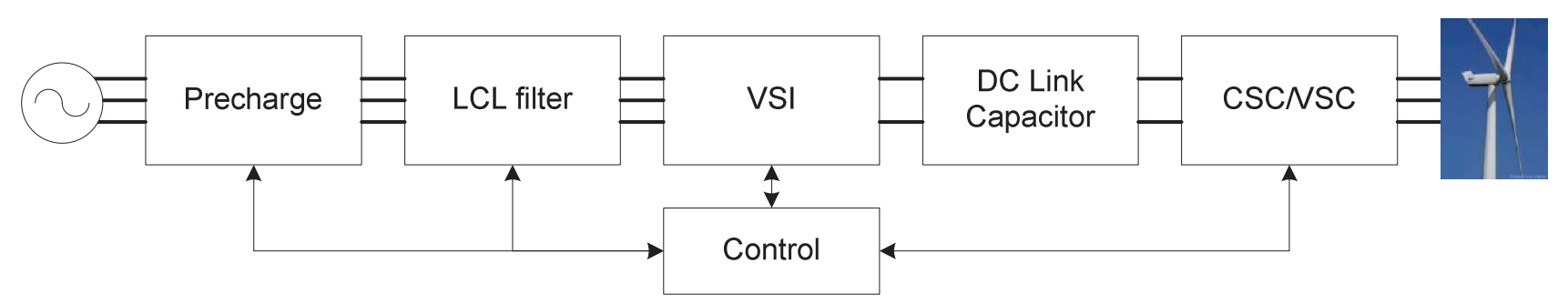

Figure 1. Configuration of the full power conversion system for wind turbines.

\section{B. Copper loss:}

It is easy to calculate copper losses for low frequency sine wave. The current in LCL filter is not pure sine wave. Current is sum of fundamental $\left(\mathrm{I}_{\mathrm{f}}\right)$ and harmonic current $\left(\mathrm{I}_{\mathrm{h}}\right)$. It means winding loss in LCL filter inductor has skin and proximity losses. The total copper losses in LCL filter inductor is given by equation (8)

$$
\begin{aligned}
& I=I_{f}+\sum I_{h} \\
& P_{C u_{-} \text {loss }}=P_{c u_{-} f}+P_{c u_{-} h}=R_{f} I_{f}^{2}+\frac{1}{2} R_{h} \sum_{n} I_{h}^{2} \\
& P_{C u_{-} \text {loss }}=P_{c u_{-} f}\left[1+\frac{1}{2} \frac{R_{h}}{R_{f}} \sum_{n}\left(\frac{I_{h}}{I_{f}}\right)^{2}\right]
\end{aligned}
$$

Here, $\mathrm{P}_{\mathrm{cu} f}$ and $\mathrm{P}_{\mathrm{cu} h}$ are winding losses because of fundamental component and harmonic components respectively. $R_{f}$ is resistance for fundamental component and $R_{h}$ is the equivalent resistance for the harmonic component. $\mathrm{R}_{\mathrm{h}}$ includes the effect of the skin effect and proximity effect. The ratio of $R_{h}$ to $R_{f}$ can be calculated using equation below [4][5].

$$
\begin{aligned}
& \frac{R_{h}}{R_{f}}=\sqrt{n} A\left[F_{r s}+\frac{2\left(N^{2}-1\right)}{3} F_{r p}\right] \\
& F_{r s}=\frac{\sinh (2 A \sqrt{n})+\sin (2 A \sqrt{n})}{\cosh (2 A \sqrt{n})-\cos (2 A \sqrt{n})} \\
& F_{r s}=\frac{\sinh (A \sqrt{n})-\sin (A \sqrt{n})}{\cosh (A \sqrt{n})+\cos (A \sqrt{n})} \\
& A=\left(\frac{\pi}{4}\right)^{\frac{3}{4}} \frac{d}{\delta} \sqrt{\frac{d}{p}} \\
& \delta=\sqrt{\frac{\rho}{\pi \mu_{0} f_{s w}}}
\end{aligned}
$$

In the equations (10) \& (11), $\mathrm{n}$ is the order of the harmonics, $\mathrm{N}$ is the number of turns, $\mathrm{F}_{\mathrm{rs}}$ and $\mathrm{F}_{\mathrm{rp}}$ are skin effect and proximity effect factors. In equation (12) \& (13) $d$ is the diameter of the winding, $\mathrm{p}$ is the winding pitch (i.e. the distance between the centers of the adjacent conductors in same layer) $\rho$ is the resistivity of the winding, $\mu_{0}$ is the permeability of free space, $f_{s w}$ is the switching frequency of the VSI and $\delta$ is the skin depth of the winding. Total power loss in the LCL filter can be given by equation (14)

$$
P_{L C L_{-} \text {loss }}=P_{M S E_{-} \text {Core } \_l o s s}+P_{C u_{-} \text {loss }}
$$

\section{POWER LOSS IN VSI/VSC/CSC}

Conduction losses in IGBT can be express by equation as below:

$$
P_{I G B T_{-} \text {cond }}=\frac{1}{T} \int_{0}^{T} V_{(t)} I_{(t)} d t
$$

$\mathrm{T}$ is the fundament period. $\mathrm{V}_{(\mathrm{t})}$ and $\mathrm{I}_{(\mathrm{t})}$ are on state voltage drop across the IGBT and load current respectively. The on state voltage drop can be characterized by dynamic resistance of IGBT $r_{0}$, collector to emitter voltage Vo, and $\mathrm{B}$ is curve fitting constant as shown in equation (16) [6].

$$
P_{I G B T_{-} \text {cond }}=\frac{1}{T} \int_{0}^{T}\left(V_{o} r_{o} i_{(t)}^{B}\right) \cdot i_{(t)} d t
$$

For VSI application, PWM signal is generated by comparison of the sinusoidal control signal to the either saw tooth or triangular waveforms. The PWM is used to drive the gate driver of the IGBT. Conduction losses in this case can be provided by equation (17) [7].

$$
P_{\text {IGBT_cond }}=\frac{1}{2}\left(V_{0} \frac{I_{p k}}{\pi}+r_{o} \frac{I_{p k}^{2}}{4}\right)+m \cdot \cos \phi \cdot\left(V_{0} \frac{I_{p k}}{8}+r_{o} \frac{I_{p k}^{2}}{3 \pi}\right)
$$

The modulation index $\mathrm{m}$ is less than 1 for linear mode of the PWM. During the over modulation $1<\mathrm{m}<4 / \pi$. Conduction losses of the IGBT increase with the higher load current, collector to emitter voltage and modulation index. 


$$
P_{I G B T_{-} S W}=f_{S W} \frac{1}{T} \int_{0}^{\frac{T}{2}}\left(E_{I G B T_{-} o n}+E_{I G B T_{-} o f f}\right)\left(i_{p k}, t\right) d t
$$

IGBT switching losses is given by equation (18). The $\mathrm{E}_{\mathrm{IGBT} \_ \text {on }}$ and $\mathrm{E}_{\mathrm{IGBT} \text { off }}$ are the turn on and turn off switching losses of the IGBT and $f_{s w}$ is the switching frequency of the IGBT. Switching losses are directly proportional to the switching frequency, load current and collector to emitter voltage. $\mathrm{E}_{\mathrm{IGBT} \text { on }}$ and $\mathrm{E}_{\mathrm{IGBT} \text { off }}$ are depends on the gate resistance of the gate drive board. Higher the gate resistance leads to increase in switching losses but it will help reduce the $\mathrm{dv} / \mathrm{dt}$ and di/dt and EMI of VSI and in addition it help increase short circuit capability of power module.

Similarly diode conduction losses for VSI application can be given by equation (19). $V_{\text {toff }}$ the voltage across the diode and $r_{t}$ is the dynamic resistance of the diode. Diode turn on losses is negligible compare to the reverse recovery voltage. Diode switching losses is given by the equation (20).

$$
\begin{aligned}
& P_{\text {Diode_cond }}=\frac{1}{2}\left(V_{\text {toff }} \frac{I_{p k}}{\pi}+r_{t} \frac{I_{p k}^{2}}{4}\right)-m \cdot \cos \phi \cdot\left(V_{\text {toff }} \frac{I_{p k}}{8}+r_{t} \frac{I_{p k}^{2}}{3 \pi}\right) \\
& P_{\text {Diode_SW }}^{2}=f_{S W} \frac{1}{T} \int_{0}^{\frac{T}{2}} E_{\text {Diode_off }}\left(i_{p k}, t\right) d t
\end{aligned}
$$

IGBT and diode switching losses calculation depends on actual measurement of the $\mathrm{E}_{\mathrm{IGBT} \text { on, }} \mathrm{E}_{\mathrm{IGBT} \text { off }}$ and $\mathrm{E}_{\text {Didoe_off. }}$ The measurement can be made using double pulse test. The two gate pulses are applied to the IGBT. The first pulse is to close the IGBT and ramp up the current. Since the load is an inductor, the current should ramp linearly. The pulse is terminated when the current has reached the desired value. The current will switch to the freewheeling diode. This gives IGBT turn of losses and diode turn on losses. The second pulse is applied to turn on the IGBT at the present current level, which gives IGBT turn on losses and diode turn off losses. The flow of currents is shown in Figure. 2.

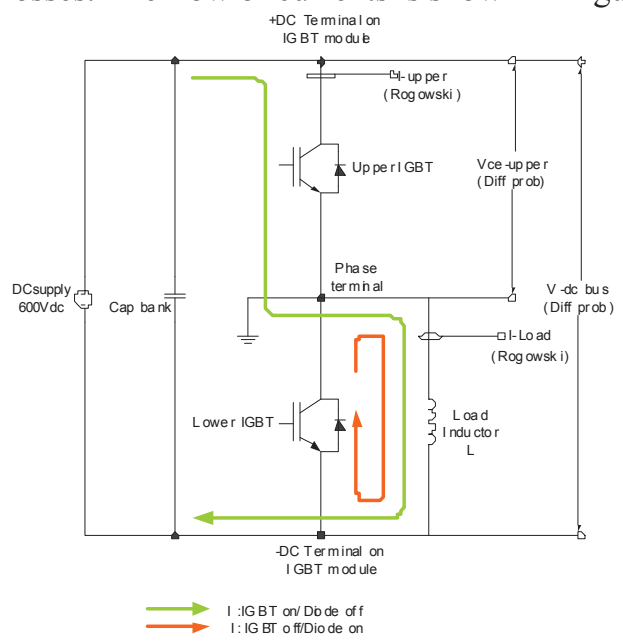

Figure 2. Double pulse test circuit.

VSI power losses can be reducing by use of the appropriate power modules. For low frequency high power application $\mathrm{Si}$ power modules have lower power losses. For higher frequency application $\mathrm{SiC}$ power modules have lower power losses compare to $\mathrm{Si}$ power modules [9]. The watt loss analysis is performed for two different Infenion power modules 1. FF600R12IS4F with $\mathrm{SiC}$ diode for high frequency application and 2. FF600R12IE4 for low frequency application. Figure 3 shows the conduction and switching losses for IGBT. The $\mathrm{SiC}$ module conduction losses are higher than $\mathrm{Si}$ module. At $4 \mathrm{kHz}$ switching frequency the switching losses in $\mathrm{SiC}$ unit is relatively lower compare to $\mathrm{Si}$ module. $\mathrm{SiC}$ switching loss at $8 \mathrm{kHz}$ are significantly lower than Si module. Figure 4 shows the comparison between $\mathrm{SiC}$ and $\mathrm{Si}$ modules diode conduction and switching losses. Diode reverse recovery losses is highest in Si module at $8 \mathrm{kHz}$. Figure 5 shows total power loss in $\mathrm{Si}$ and $\mathrm{SiC}$ module at $4 \mathrm{kHz}$ and $8 \mathrm{kHz}$ switching frequency. For low frequency application $(<4 \mathrm{kHz}) \mathrm{Si}$ power is better $\mathrm{Vs} \mathrm{SiC}$ module and vice versa for high frequency $(>8 \mathrm{kHz})$ application. It is very important to select appropriate modules, its placement on heat sink and low inductance bus structure to reduce the losses in power structure. The total loss in the VSI is given by equation (21). $\mathrm{n}_{1}$ and $\mathrm{n}_{2}$ are number of IGBT and Diode in VSI Power Structure.

$$
P_{V S I_{-} \text {loss }}=n_{1}\left(P_{\text {IGBT_Cond }}+P_{\text {IGBT_S } S W}\right)+n_{2}\left(P_{\text {Diode_cond }}+P_{\text {Diode_SW }}\right)(21)
$$

The losses in the VSI is also depend on the form of pulse width modulation (PWM) that is used to control inverter switching to achieve a variable voltage, variable frequency output [8]. There are mainly two types of PWM technique used for VSI. 1. Continuous PWM (CPWM), 2. Discontinuous PWM (DPWM). In CPWM, the modulating signal is a continuous time varying signal, examples of which include conventional sinusoidal PWM (SPWM), space vector PWM (SVPWM), and third-harmonic injection PWM (THIPWM) as shown in Figure 6. SVPWM was developed to increase the dc-link utilization from $\mathrm{m}_{\mathrm{a}}=1$ in the case of SPWM to $\mathrm{m}_{\mathrm{a}}=1.15$ where $\mathrm{m}_{\mathrm{a}}$ is the modulation index. In case of the DPWM modulation technique, the modulating signal is clamped to the dc-link voltage for one third of the period and there are no switching instants during this time. The starting phase angle $\psi$ determines the zerosequence signal and, hence, the type of DPWM scheme. In DPWM0 $\psi=0$; DPWM1 $\psi=\pi / 6$; and DPWM2 $\psi=\pi / 3$. DPWM also provides a linear range of modulation index of $\mathrm{m}_{\mathrm{a}}=1.15$, but by utilizing a discontinuous modulating signal, it reduces switching losses to one third of the SVPWM or THIPWM as given by equation (21). The conduction losses in case of DPWM increase but the overall losses in power module is lower compare to SVPWM. DPWM with $\psi=0$ is shown in Figure 7.

$$
P_{\text {DPWM }_{-} S W}=\frac{1}{3} P_{\text {SVPWM (THIPWM })_{-} S W}
$$




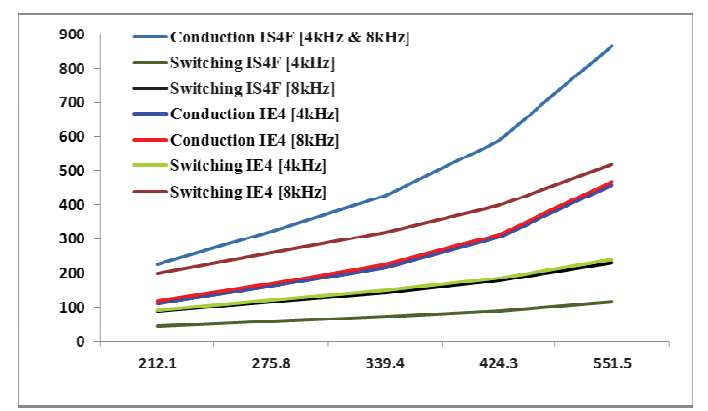

Figure 3. IGBT conduction and switching losses for $\mathrm{Si}$ and $\mathrm{SiC}$ unit at different load currents.

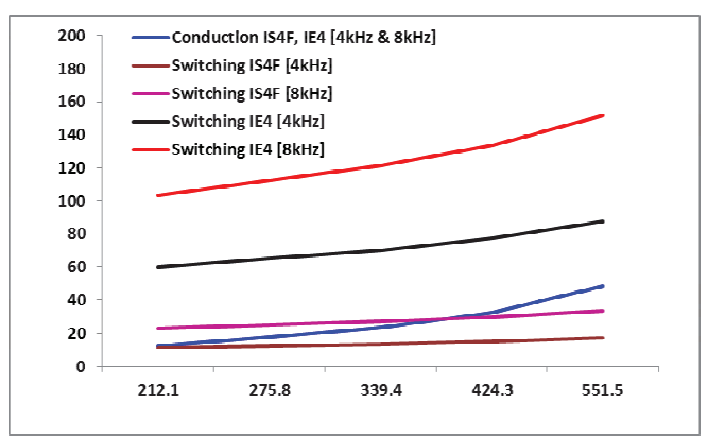

Figure 4. Diode conduction and switching losses for $\mathrm{Si}$ and $\mathrm{SiC}$ unit at different load currents.

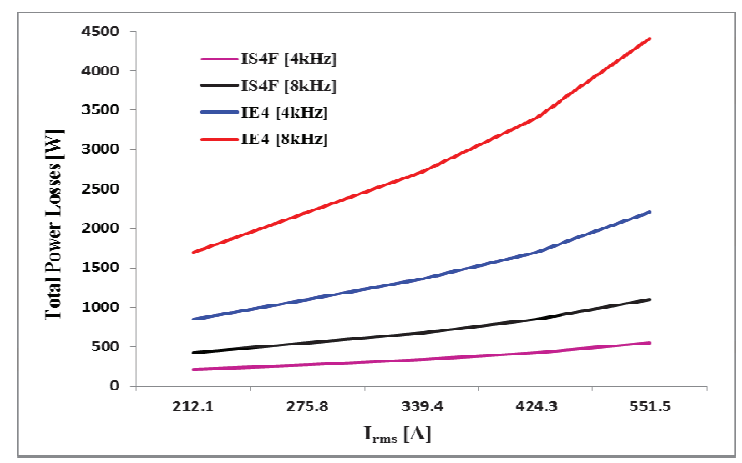

Figure 5. Total power losses for $\mathrm{Si}$ and $\mathrm{SiC}$ unit at different load currents.

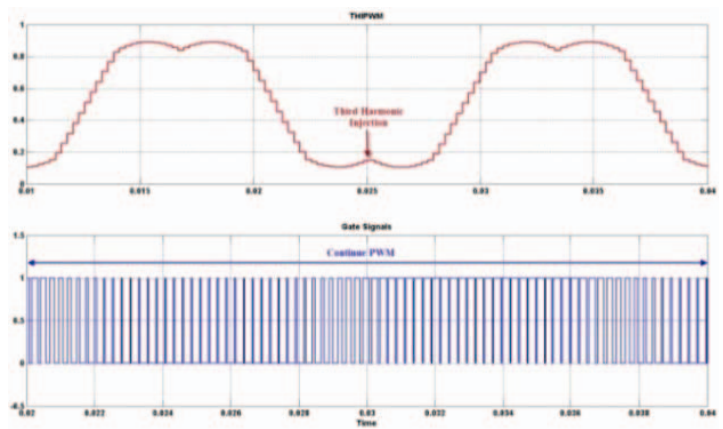

Figure 6. THIPWM control signal and PWM gate pulse.

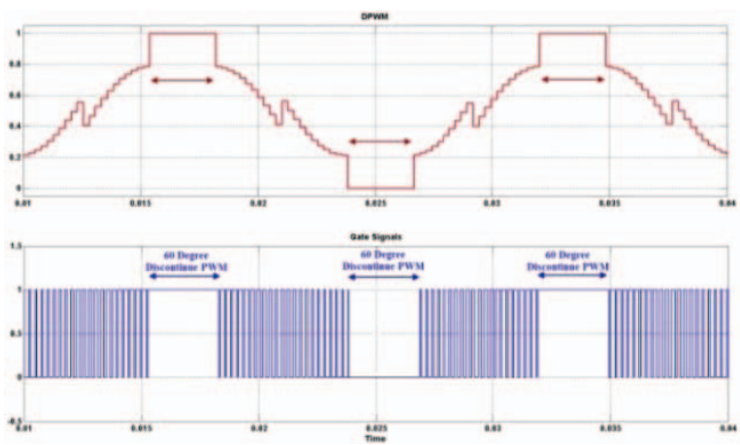

Figure 7. DPWM control signal and PWM gate pulse.

IV. POWER LOSS IN DC LINK CAPACITOR AND MISCELLANEOUS LOSSES

DC capacitor bank is made up of combination of the series parallel connected capacitors to meeting the voltage withstand and capacitance requirement for the system. Every capacitor has different leakage current. To keep the balance voltage across each capacitor in series connected capacitors required balancing resistor. Balancing resistor requirement is based on type of capacitor and leakage current. In addition each capacitor has equivalent series resistor (ESR). The total losses in DC link capacitors are given by equation (22). $R_{b}$ is the balancing resistor and $R_{E S R}$ is the capacitor bank equivalent series resistor. Lower leakage current capacitor leads to higher value of $\mathrm{R}_{\mathrm{b}}$ and low ESR capacitor leads to lower overall DC link loss.

$$
P_{\text {DClink_loss }}=\frac{V_{d c}^{2}}{R_{b}}+I_{d c} R_{E S R}
$$

There are some miscellaneous losses like loss in switch disconnect, fuses, bus bar or wires, control transformers and fan/blower. Even though these losses are lower compare to the power module and LCL filters losses, it is important to consider for efficiency calculation. Some losses like control transformer and fan/blower losses are continues losses even though unit is not running. All this losses can be lump together as miscellaneous losses $\mathrm{P}_{\text {miscloss }}$. Higher efficiency fan/blower with speed control, copper bus bars with tin plating, and lower contact resistance switch disconnect leads to lower the miscellaneous losses.

\section{EFFICIENCY AND STAND BY MODE OF OPERATION}

The losses in power conversion system is dominated by LCL filter and VSI/VSC/CSC power structures. For higher switching frequency application $(>=8 \mathrm{kHz}), \mathrm{SiC}$ power modules will reduce the losses in VSI/VSC/CSC. The higher switching frequency reduces the size of LCL to attenuate the switching frequency component but it increase the core loss in LCL. The core losses can be improved by using better core material and reduces lamination thickness.

For low switching frequency application, Si power modules are better option compare to $\mathrm{SiC}$ power modules. The size of the LCL gets bigger to attenuate the low switching frequency $(<=4 \mathrm{kHz})$ components but the core losses are 
lower. With use of the DPWM technique, VSI switching losses can be further reduces. It is important to note that DPWM increase the losses in LCL. The selection of SVPWM Vs DPWM method requires balance power loss balance between LCL and VSI.

In wind power application, $40 \%$ of the time power conversion devices (LCL, VSI/VSC/CSC) are idle (not generating active power) because of unavailability of the wind. In idle mode, VSI and VSC/CSC are still modulating at no load. The circulating current through LCL filter generates the core losses in inductors. To keep the filter and VSI/VSC unit cool, fan/blower need to run all the time. It means when unit is not generating any power it is actually consumes significant energy. In order to reduce power loss in LCL filter and VSI/VSC unit and reduce energy consumption by fan/blower, place the power conversion devices in standby mode. In standby mode, only control power needs to keep it alive. Disconnect and/or shut down devices which produce power losses or consume energy. The flow chart of the standby mode operation is given below.

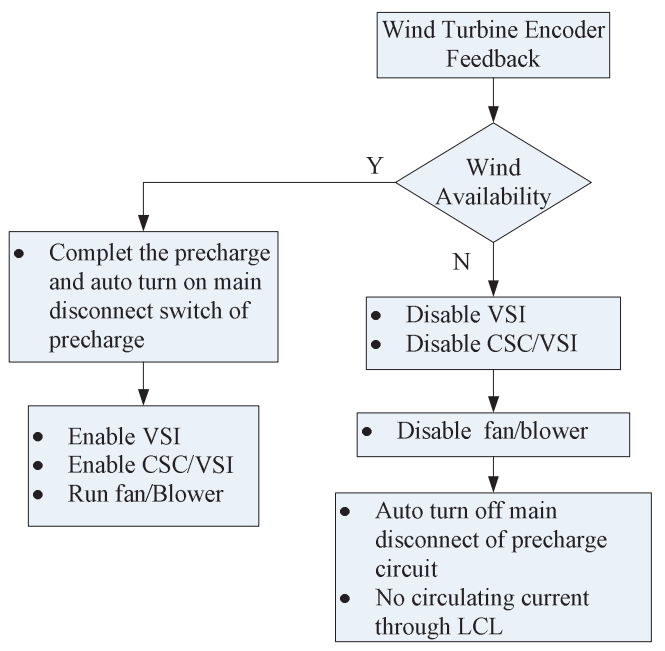

Figure 8. Flow chart for standby mode of operation.

\section{EXPERIMENTAL RESULTS}

Efficiency of the $300 \mathrm{HP}$ VSI-VSC unit is calculated and compare with actual measurement. Infineon 450A IGBT power module is used in VSI/VSC. The same power module is used for double pulse test setup is shown in Figure 9. Using double pulse set up, the $\mathrm{E}_{\mathrm{IGBT} \text { on, }} \mathrm{E}_{\mathrm{IGBT} \text { off }}$ and $\mathrm{E}_{\text {Didoe_off }}$ measurement are performed. It is used for the calculation of the switching losses of the IGBT and Diode. Figure 10 and 11 shows the IGBT on and off losses waveform at $450 \mathrm{~A}$. IGBT on loss is $59 \mathrm{~mJ}$ and IGBT off loss is $89 \mathrm{~mJ}$. Using this measurement value as well as IGBT and Diode conduction and switching loss equations, watt losses are calculated for 2-level VSI and VSC in regenerative mode of operation. Conditions for VSI and VSC watt loss calculations are shown in Table 1. The losses are calculated at $4 \mathrm{kHz}$ switching frequency with $\max$ junction temperature at $125 \mathrm{C}$. Assumption for grid and wind generator side power factors are .98 and 0.88 respectively. VSI and VSC combine watt loss is $6.918 \mathrm{~kW}$. Table 3 shows the breakdown of the losses in the VSI in inverter and rectifier mode. The losses are calculated for regenerative application, where the energy is feedback to grid. IGBT conduction and switching losses higher compare to the diode loss in case of rectifier mode. Diode conduction losses are higher compare to IGBT conduction loss in rectifier mode.

Table 1. Conditions for VSI watt loss measurement

\begin{tabular}{|l|c|}
\hline Switching Frequency & $4000 \mathrm{~Hz}$ \\
\hline Modulation Index & 1 \\
\hline Fundamental Frequency & $60 \mathrm{~Hz}$ \\
\hline Junction Temperature & $125 \mathrm{C}$ \\
\hline Case Temperature & $80 \mathrm{C}$ \\
\hline Inverter Power Factor & 0.98 \\
\hline Rectifier Power Factor & 0.88 \\
\hline
\end{tabular}

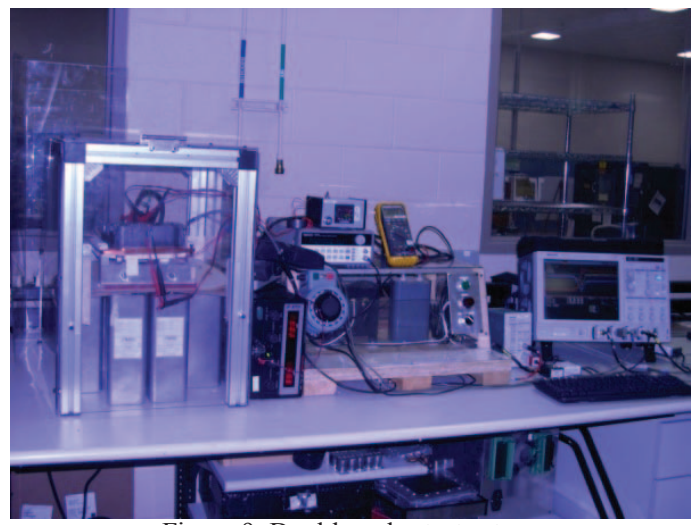

Figure 9. Double pulse test setup.

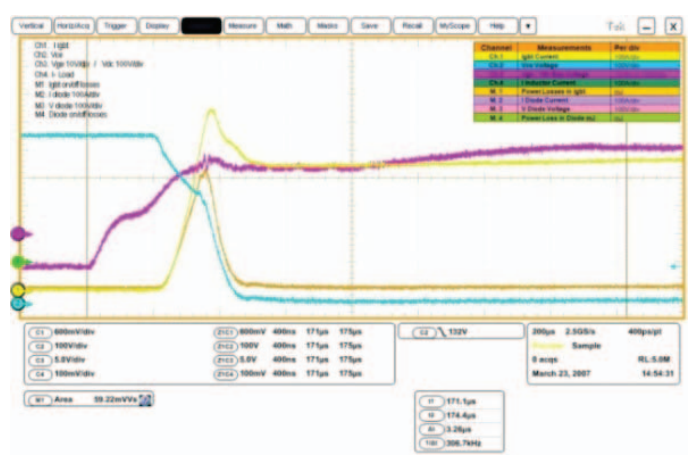

Figure 10. IGBT ON loss at 450A.

Table 2. Power loss breakdown in LCL filter.

\begin{tabular}{|c|c|c|c|c|}
\hline $\begin{array}{c}\mathbf{L}_{\mathrm{g}} \text { Cu loss } \\
{[\mathbf{W}]}\end{array}$ & $\begin{array}{c}\mathbf{L}_{\mathrm{g}} \text { Core loss } \\
\text { [W] }\end{array}$ & $\begin{array}{c}\mathbf{L}_{\mathbf{c}} \text { Cu loss } \\
{[\mathbf{W}]}\end{array}$ & $\begin{array}{c}\mathbf{L}_{\mathbf{c}} \text { Core loss } \\
{[\mathbf{W}]}\end{array}$ & $\begin{array}{c}\mathbf{P}_{\mathbf{L C L}_{2} \text { loss }} \\
{[\mathbf{w}]}\end{array}$ \\
\hline 520 & 186 & 1213 & 440 & 2359 \\
\hline
\end{tabular}

Table 3. Power loss breakdown in VSI unit in regenerative mode.

\begin{tabular}{|l|c|r|r|r|r|r|r|}
\hline & $\begin{array}{c}\text { Mode of } \\
\text { Operation }\end{array}$ & $\mathbf{I}_{\mathbf{R M S}}[\mathbf{A}]$ & $\begin{array}{c}\mathbf{P}_{\text {IGBT_Cond }} \\
{[\mathbf{W}]}\end{array}$ & $\begin{array}{c}\mathbf{P}_{\text {IGBT_SW }} \\
{[\mathbf{W}]}\end{array}$ & $\begin{array}{c}\mathbf{P}_{\text {Diode_Cond }} \\
{[\mathbf{W}]}\end{array}$ & $\begin{array}{r}\mathbf{P}_{\text {Diode_SW }} \\
{[\mathbf{W}]}\end{array}$ & $\begin{array}{c}\mathbf{P}_{\text {VSL_loss }} \\
{[\mathbf{W}]}\end{array}$ \\
\hline Rectifier & Regen & 360 & 109 & 330 & 48 & 55 & 3252 \\
\hline Inverter & Regen & 360 & 70 & 353 & 129 & 59 & 3666 \\
\hline
\end{tabular}




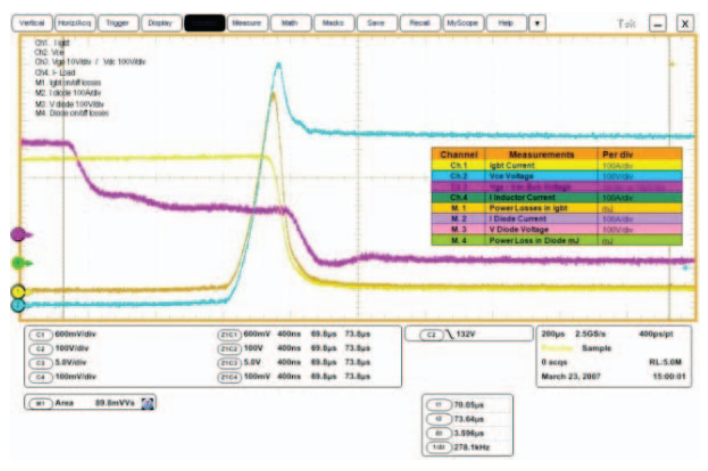

Figure 10. IGBT off loss at 450A.

For $300 \mathrm{Hp}$ unit the grid side inductor $\mathrm{Lg}$ is $60 \mathrm{uH}$ and line side inductor is $180 \mathrm{uH}$. Using inductor core loss and copper loss equation inductor losses are calculated as shown in Table 2. Control transformer rated for 750VA, and blower input rating is $240 \mathrm{VAc}, 2 \mathrm{~A}$ (480VA). Balancing resistor for the DC capacitor bank is $8 \mathrm{k} \Omega$ which translates in to $61 \mathrm{~W}$ loss. ESR of the DC capacitor bank is $2 \mathrm{~m} \Omega$ leads to $256 \mathrm{~W}$ loss. The total loss in system is equal to $10.34 \mathrm{~kW}$ which does not include Bus bars, fuse and switch disconnect losses. The calculated efficiency of the power conversion system is $95.9 \%$. The actual measurement of the unit efficiency was performed using yokogawa power meter. The measurement is shown in Table 4. The input voltage and current waveform are shown in Figure 11. The efficiency is in range of $96 \%$, which is very close to the calculated efficiency.

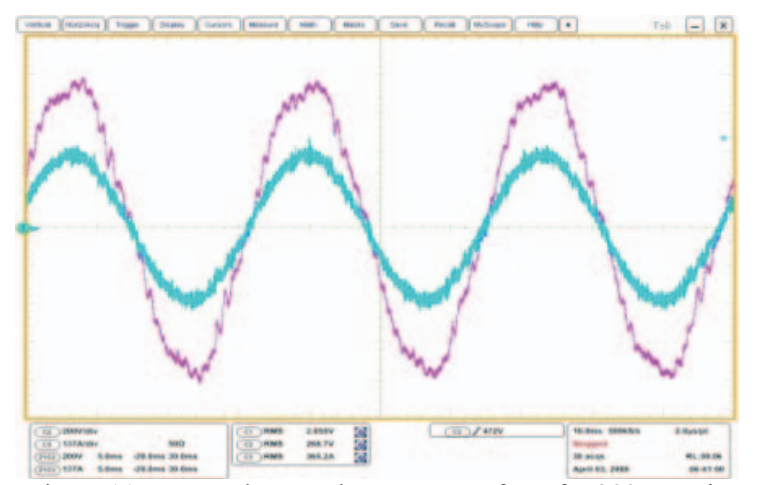

Figure 11. Input voltage and current waveform for $300 \mathrm{Hp}$ unit

Table 4. Measured efficiency for $300 \mathrm{Hp}$ unit at different load condition.

\begin{tabular}{|c|c|c|c|c|c|c|c|c}
\hline Unit Loading & $\begin{array}{c}\text { Power } \\
\text { Out } \\
\text { (Watts) }\end{array}$ & $\begin{array}{c}\text { Power In } \\
\text { (Watts) }\end{array}$ & $\begin{array}{c}\text { Drive } \\
\text { Efficiency }\end{array}$ & $\begin{array}{c}\text { Voltage } \\
\text { In }\end{array}$ & $\begin{array}{c}\text { Current } \\
\text { In }\end{array}$ & $\begin{array}{c}\text { Voltage } \\
\text { Out }\end{array}$ & $\begin{array}{c}\text { Current } \\
\text { Out }\end{array}$ & $\begin{array}{c}\text { Power } \\
\text { Factor }\end{array}$ \\
\hline $180 \mathrm{~A}(50 \%)$ & 117570 & 121850 & 96.49 & 464.75 & 158.63 & 445.47 & 177.95 & 0.95 \\
\hline $270 \mathrm{~A}(75 \%)$ & 170020 & 176390 & 96.39 & 452.84 & 228.55 & 416.17 & 263.02 & 0.98 \\
\hline $360 \mathrm{~A}(100 \%)$ & 246210 & 255630 & 96.31 & 466.82 & 317.54 & 447.9 & 351.53 & 1.00 \\
\hline
\end{tabular}

If power conversion unit is running at no load condition during unavailability of the wind, the circulating current though the LCL unit for 300HP is around 35Arms. The total core loss in LCL is around 626W. The loss in capacitor bank is $61 \mathrm{~W}$ across balancing resistor. Assume negligible losses in VSI, VSC, bus bars and fuses at no load condition. Blower is still required to keep the LCL and other component cool. Total watt loss is around $1.067 \mathrm{~kW}$ when power conversion unit running at no load condition. By placing the unit in to standby mode, $1 \mathrm{~kW}$ watt loss can be avoided for $300 \mathrm{Hp}$ unit. In wind farm, multiple MW units are installed. Placing these units in standby mode during unavailability of wind, significant about of energy can be saved.

\section{CONCLUSION}

In this paper, calculation of efficiency for power conversion devices is provided in detail. LCL filter, VSI and DC link capacitors power losses are calculated. Calculation of the VSI switching losses requires IGBT and Diode turn on and turn off losses. Double pulse test method to measure the IGBT and Diode turn on and turn off loss are discussed in detail and verify with experimental setup. The calculated efficiency is compared with the measured efficiency of power conversion device. Measured efficiency is very close the calculated efficiency. Power conversion unit standby mode of operation is provided using flow chart. The total energy saving by standby mode of operation for $300 \mathrm{Hp}$ unit is provided in experimental results.

\section{REFERENCES:}

[1] Y. Chen, P. Pillay, “An improved formula for lamination core loss calculations in machines operating high frequency and high flux density excitation." IEEE industry application conference, vol. 2, pp. 759- 766, 2002.

[2] A. Van den Bossche, V. C. Vencislav, G. B. Georgi, "Measurement and loss model of ferrites with non- sinusoidal waveform." IEEE power electronic specialist conference, vol. 6, pp. 4814-4818, 2004

[3] J. Li, T. Abdallah, C. R. Sullivan, "Improved calculation of core loss with non-sinusoidal waveforms." IEEE industry application conference, vol. 4 pp 2203-2210, 2001

[4] N. Kondrath, M. K. Kazimierczuk, "Inductor winding loss owing to skin and proximity effects including harmonics in nonisolated pulse width modulated DC- DC converters operating in continuous conduction mode." IET power electronics, vol. 3, pp. 989-1000, 2010

[5] N. Nymand, Udaya K. Madawala, M. A. E. Anderson, B. Carsten, O. S. Seiersen, "Reducing AC winding losses in highcurrent, high-power inductors", IEEE industrial electronics, $35^{\text {th }}$ annual conference of IECON, pp. 777-781, 2009

[6] F. Blaabjerg, J. K. Pedersen, S. Sigurjonsson, A. Elkaer, "An extended model of power losses in hard- $\quad$ switched IGBT inverters". IEEE industry application conference, vol. 3, pp. 14531463,1996

[7] Dimensioning program IPOSIM for loss and thermal calculation of Infineon IGBT modules. Resource Infineon Inc. Application notes.

[8] W. Yunxiang, M. A. Safi, A. M. Knight, R. A. Mcmohan, "Comparison of the effects of continuous and discontinuous PWM schemes on power losses of the voltage sourced inverters for induction motor drives", IEEE transaction on power electronics, vol. 26, pp 182-191, 2011

[9] H. Meerzahi, S. Bhattacharya, S. Ryu, A. Agarwal, "Design comparison of $6.5 \mathrm{kV}$ Si-IGBT, 6.5kV SiC JBS diode, and $10 \mathrm{kV}$ SiC MOSFETs in megawatt converters for shipboard power system. IEEE electric ship technologies symposium, pp. 248-253, 2011 